Document downloaded from:

http://hdl.handle.net/10251/120137

This paper must be cited as:

Ligardo-Herrera, I.; Gómez-Navarro, T.; Gonzalez-Urango, H. (2018). Application of the ANP to the prioritization of project stakeholders in the context of responsible research and innovation. Central European Journal of Operations Research. 1-23.

https://doi.org/10.1007/s10100-018-0573-4

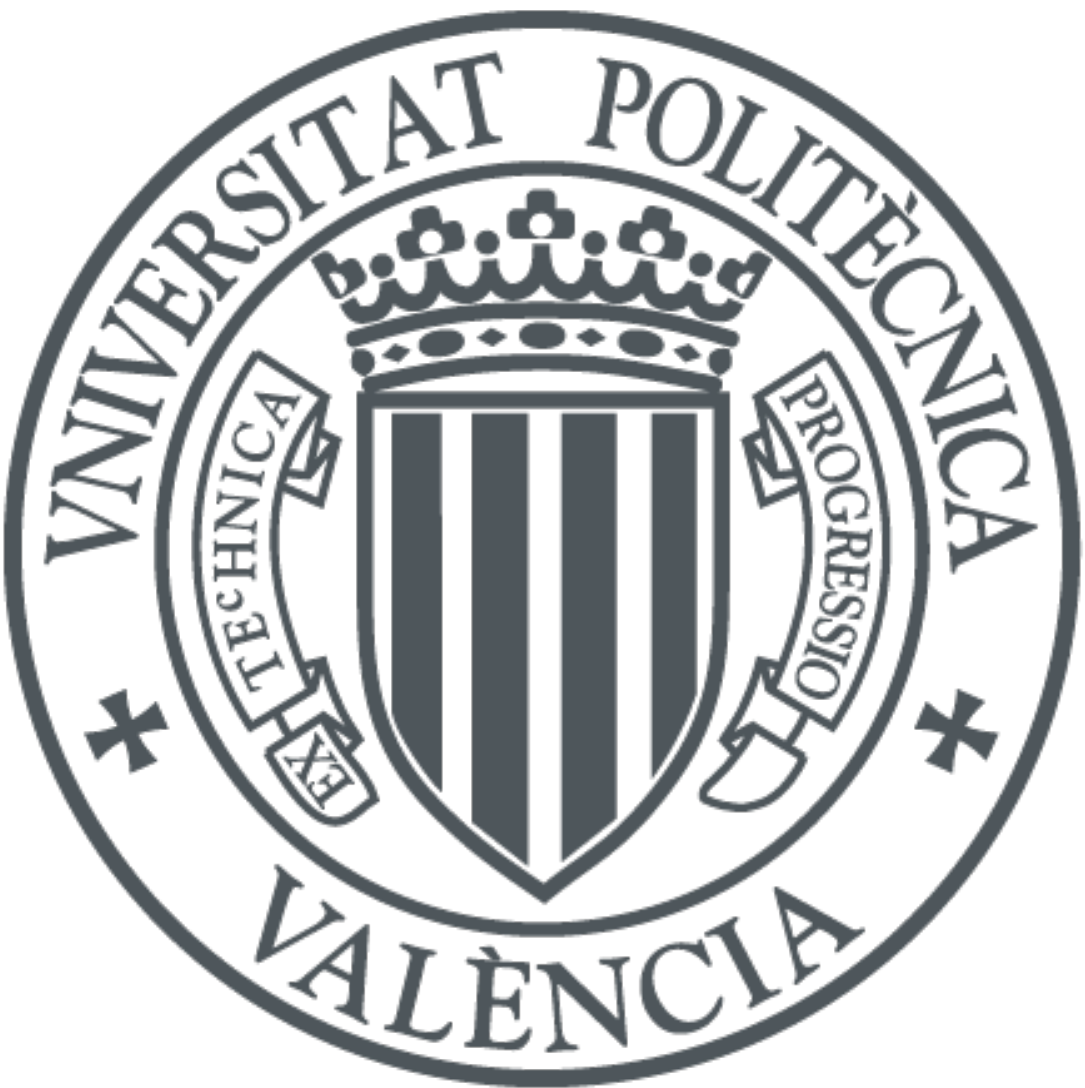

The final publication is available at

https://doi.org/10.1007/s10100-018-0573-4

Copyright Springer-Verlag

Additional Information 


\title{
APPLICATION OF THE ANP TO THE PRIORITIZATION OF PROJECT STAKEHOLDERS IN THE CONTEXT OF RESPONSIBLE RESEARCH AND INNOVATION.
}

\author{
Ivan Ligardo-Herrera ${ }^{1,2, *}$, Tomás Gómez-Navarro', Hannia Gonzalez-Urango ${ }^{2,3}$ \\ 1 Institute of Energy Engineering IIE, Universitat Politècnica de València, Valencia 46022, Spain; \\ tgomez@dpi.upv.es \\ 2 Universidad Simón Bolívar, Barranquilla, Colombia, 080002. \\ 3 Ingenio (CSIC-UPV), Universitat Politècnica de València, 46022 Valencia, Spain; \\ hangonur@doctor.upv.es; \\ *Correspondence: ivliher@doctor.upv.es; Tel.: +34-627-117-144
}

\begin{abstract}
This paper presents a methodology to assess the stakeholders' influence in a research project within the context of Responsible Research and Innovation. The methodology is based on a combination of the multicriteria decision making technique Analytic Network Process and the key areas of responsible research. The method allows ranking and ordering the project's stakeholders based on their influence upon its responsibility. The purpose of such an assessment is to help research teams to more efficiently devote their limited resources to stakeholder management.
\end{abstract}

The procedure is applied to a case study of the Information and Communication Technology business sector. It is an ongoing project at an early phase of development. Influential stakeholders have been identified first, and have been further classified into groups based on their relative importance. The assessment of their influence has been based on up to 16 different criteria, mainly belonging to the framework of Responsible Research and Innovation.

In the case study, the most influential criterion was the Capability to promote public engagement, while Developers were found to be the stakeholders most contributing to the research project responsibility. However, as explained, this is a temporary situation, valid for the current project development situation. It may vary over time as criteria vary in weight and stakeholders vary in influence.

Keywords: Stakeholders management, Analytic Network Process (ANP), Responsible Research and Innovation (RRI).

\section{INTRODUCTION}

\subsection{Responsible research and innovation}

The European Commission has been promoting a cross-cutting issue named "Responsible Research and Innovation (RRI)". The aim is to encourage researchers to take into consideration the potentially unwanted impacts of their research process and of its outcomes, and make responsible decisions about them. The most widely used definition of RRI could be the one given by Von Schomberg (von Schomberg 
2011) (p. 9): '(RRl) is a transparent, interactive process by which societal actors and innovators become mutually responsive to each other with a view to the (ethical) acceptability, sustainability and societal desirability of the innovation process and its marketable products'. Therefore, researchers and Innovators are expected to answer questions from society about the aims and the consequences of any research, or innovation activity (European Commission 2011).

Therefore, the works under the auspices of the European Commission have found that RRI must involve a dialogue with stakeholders during the whole research and innovation process. The aim being to better align with the stakeholders' interests both the research process and its outcomes. Six key areas for that dialogue were first identified: Public Engagement; Gender Equality; Science Education; Open Access; Ethics; and Governance (European Commission 2012). More recently, two more areas have been added, Sustainability (environmental); and Social Justice (Strand et al. 2015).

Furthermore, Burget et al. (2017) added to the RRI definition that: "Responsible Innovation is essentially an attempt to govern research and innovation in order to include all the stakeholders and the public in the early stages of research and development. The inclusion of different actors and the public is, in turn, meant to increase the possibilities of anticipating and discerning how research and innovation can or may benefit society as well as preventing any negative consequences from happening" (Burget et al. 2016) (p. 15).

According to Koops and Stilgoe et al. (Stilgoe et al. 2013; Koops 2015), RRI can be conceived as an approach and an ideal. The first one involves the available tools and how we can innovate responsibly. The second involves the inclusion and promotion of self-learning via Anticipation, Reflection, Deliberation and Responsiveness of the innovation process (de Jong et al. 2016). Stakeholders are expected to participate from the beginning in the Anticipation stage, at which the potential benefits and harm of the research and its possible outcomes are envisaged.

A consortium funded by the EU developed the project RRI-TOOLS, (https://www.rritools.eu/). In it they have considered RRI as: "doing science and innovation with society and for society, including the involvement of relevant stakeholder groups which are very upstream in the process of research and innovation to align its outcomes with the values and expectations of society". Under this umbrella, scientist share with society's stakeholders the traditional dynamic of setting agendas and exploring desirable futures to be reached with their research. Stakeholders are now more than just beneficiaries, or users of research and innovation (Stahl and Coeckelbergh 2016).

The insertion of relevant stakeholders in research and innovation activities over time is complex, but necessary as the context has a significant impact on the utility of RRI 
activities (van de Poel et al. 2017). This procedure considers an inclusive deliberation with a broader set of stakeholders related to the aim of research, its processes and, also, a disposition of stakeholders to act according to novel perceptions (Owen et al. 2013).

However, authors have found a wider than expected reluctance to really engage with stakeholders (Referencia a nuestro paper en Sustainability). Barriers to stakeholder management in research and innovation projects are, among others, i) lack of the skills for managing stakeholders, i.e. difficulties in identifying stakeholders, their interests and powers, who represent or speak on behalf of them, how to engage in a productive collaboration, etc. ii) protecting innovation, avoiding key information getting to the competitors; iii) resources needed for educating stakeholders so that they can really help; or iv) its perception as an obstacle to the agility of the research practices.

One way to facilitate the process and answer those problems is to prioritize the influential stakeholders. This way, the research team can apply the "Pareto principle" and anticipate the majority of issues related to their responsibility, by working with a reduced set of important stakeholders. Providing those teams can really determine who the most influential stakeholders are.

\subsection{Stakeholder's influence in research projects}

There is extensive literature on stakeholder management and evaluation (AragonésBeltrán et al. 2017). In fact, Corporate Social Responsibility (CSR) and Project Management theories, have already highlighted the relevance of a detailed analysis of stakeholders and their impact (Dahlsrud 2006).

Stakeholder management starts by the identification of stakeholders and the analysis of their interests or expectations, and their impacts on the project (Brugha 2000). There are several other stakeholder analyses like the one which classifies them in terms of Power, Legitimacy and Urgency (Mitchell et al. 1997); the one based on their Assertiveness and Cooperativeness; the analysis of Influence and Interest in the project (Colin and Ackermann 1998; De Lopez 2001); or the one based on a map of Impact for stakeholders vs Impact for the Project promoters.

Nevertheless, none of those analyses are suitable for assessing the influence of stakeholders on the responsibility of a research and innovation project, or of the future exploitation of its outcomes. Features like interests, power, legitimacy, impact for the promoters, etc. are too indirectly related to RRI.

Hence, the research questions this paper seeks to answer are:

i) In which way can a stakeholder contribute to the responsibility of a project in the framework of RRI? and 
ii) How to prioritize stakeholders based on their contribution to the responsibility of a research and innovation project?

Thus, this paper proposes a methodology for evaluating the stakeholders of a research project in the framework of RRI. For this goal we apply the Analytical Network Process (ANP).

The rest of the paper is organized as follows. In the next two sections, a detailed description of the methodology with the help of a case study is presented, explaining the procedure and the results of the application. Finally, conclusions and some challenges posed by this work are included.

\section{METHODOLOGY PROPOSED}

To solve the research questions, a methodology is put forward based on the combination of two realms: the RRI approach as the framework and the Analytic Network Process (ANP) as the tool.

\subsection{Analytic Network Process}

ANP is a multicriteria decision making (MCDM) technique that allows the relative measurement of intangible criteria, as proposed by (Saaty 2001). The ANP procedure generalized his original Analytic Hierarchy Process AHP (Saaty 1990). Both theories provide a framework to address decision making or problem assessment. AHP has been accepted as a leading MCDM method due to its ease of use for preferential information elicitation from expert subjects, in order to assign priorities to the criteria or indicators involved in a problem (Sólnes 2003; Ramzan et al. 2008; Šijanec et al. 2009; Akbari et al. 2017). However, AHP does not allow us to consider the interdependencies among criteria.

For this reason, the use of the ANP is proposed because it develops a better representation of the complex interactions, interdependencies and feedback relationships among the different components of problems like those of RRI (Saaty and Peniwati 2008; Sipahi and Timor 2010; Botero et al. 2015; De Lotto et al. 2016; Shiau and Chuen-Yu 2016; Wu and Cui 2016). This way, besides, it avoids the compensation problem of other models (Peris et al. 2013). A problem is modelled as a structure or network system composed of different elements (criteria and alternatives), grouped in clusters and connected to each other by influences among them.

The main steps to solve a multicriteria decision-making problem using ANP are the following (Saaty 2001): 
1. Identifying the components and elements of the network and their relationships. The problem is then structured as a network.

2. Conducting pairwise comparisons of the elements. Elements are compared using Saaty's 1-to-9 scale. The ANP prioritizes not just elements but also groups or clusters of elements as is often necessary in the real world.

3. Placing the resulting relative importance weights (eigenvectors) in pairwise comparison matrices within the matrix (unweighted matrix).

4. Conducting pairwise comparisons of the clusters.

5. Weighting the blocks of the unweighted matrix, by the corresponding priorities of the clusters, so that it can be column-stochastic (weighted matrix).

6. Raising the weighted matrix to limiting powers until the weights converge and remain stable (limit matrix).

7. Obtaining the prioritizations of the elements according to any of the columns of the limit matrix.

8. Once the results are obtained, in case some alternatives achieve very similar results, a sensitivity analysis should be carried out in order to demonstrate the robustness of the ranking obtained.

Mathematical foundations of AHP and ANP can be found in Saaty (Saaty 1990, 1994, $2005,2008)$. Several authors introduce the use of ANP in different areas; a review of the main developments in the AHP and ANP can be found in Vaidya and Kumar (Vaidya and Kumar 2006), Görener (Görener 2012), and Sipahi (Sipahi and Timor 2010).

Some recent applications of ANP to the field of stakeholder management are found in (Sangle and Babu 2007; Bhupendra and Sangle 2017) and (Rosso et al. 2014). Evidence regarding the use of ANP for assessing or developing indexes or indicators related to stakeholders of a complex problem has been found in (Aragonés-Beltrán et al. 2017).

\subsection{Methodology}

The methodology proposed is organized in three main phases: i) Designing the case study, ii) Modelling the influence assessment with an ANP model and ii) Assessing stakeholder influence for RRI by means of ANP. Fig. 1 shows an outline of the methodology. 


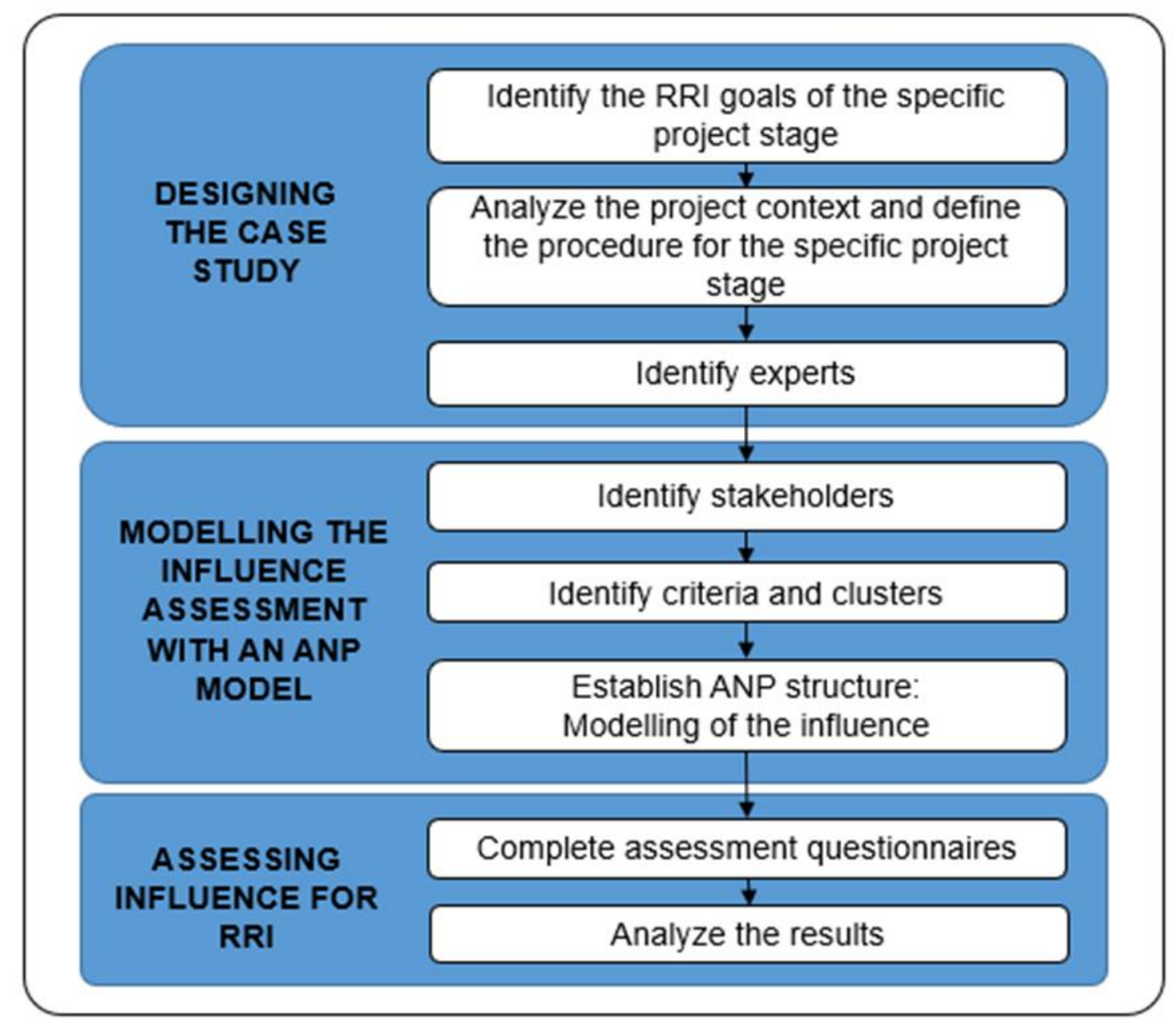

Figure 1. Methodology proposed

\subsection{Designing the case study}

This phase is divided into three stages:

i) "Identify the RRI goals of the specific project stage". At this stage, the RRI challenges to be addressed are identified by the research team based on their knowledge of the discipline. It is a preselection of RRI issues that will be later reviewed with the selected prioritized stakeholders.

The six key areas for social desirability of the research activity proposed by the European Commission help in designing a starting set of questions.

ii) "Analyze the Project context and define the procedure". This stage is carried out in two steps. The first step continues the previous stage, but focusing now on the context of the project. That means, identifying how the people, culture, infrastructure, institutions, etc. directly related to the project may be impacted socially, environmentally, economically, etc. Also, whether the impacts are positive or negative. Finally, who in particular may be most harmed or who the potential beneficiaries, partners, etc. may be.

In the second step, a procedure based on ANP is designed to determine the assessment of stakeholders. In this first contact with ANP the goal is set. For the 
purpose of this investigation, the goal of the ANP is: To assess how much stakeholders contribute to the anticipation of the responsibility of the project and the exploitation of its outcomes.

That means, the dependence among elements will be the influence of each element on the others towards the achievement of the ANP goal.

iii) "Identify Experts". In this stage it is determined who can develop an ANP model of the problem to be solved. Those experts identify the elements of the model: alternatives and criteria; arrange them into a network of several layers and clusters, the ANP model; and judge which element is preferred to which element, and to what extent, in pairwise comparisons of the same cluster.

\subsection{Modelling the influence assessment with an ANP model}

This phase is also divided into three stages:

i) "Identify Stakeholders": The Stakeholders represent the alternatives that are evaluated in the project. Thus, in this stage the work is focused on identifying all possible Stakeholders; singling them out and arranging them into a list of different stakeholders, although they may have dependencies among them; and identifying who represents those stakeholders and may act as their spokespersons.

ii) "Identify criteria and clusters": At this stage, the remaining elements are identified, i.e. decision making criteria. Hence, experts identify which characteristics of the stakeholders act as criteria for assessing their contribution to the ANP goal. Later the criteria that arise (generally not generated in an orderly manner) are hierarchically ranked into clusters using the ANP procedure.

iii) "Establish ANP structure": After having the alternatives and criteria, this third stage comprises two steps: first, experts establish the structure of the ANP model by finding out dependencies that connect elements among them. Then, questionnaires are elaborated for judging those dependencies, in this case, judging how much more one element or another influences a third one. The influence meaning the contribution to anticipating the responsibility of the innovation project.

\subsection{Assessing stakeholders' influence for RRI by means of ANP}

In this phase, experts complete the questionnaires and analyse the results. All the time they were supported by the ANP facilitators. Also they worked in coordination with the project research team. The latter will decide later how to manage the prioritized stakeholders. A detailed description of the methodology implementation is presented in the case study in the following sections. 


\section{CASE STUDY: ASSESSING STAKEHOLDERS' CONTRIBUTION TO THE ANTICIPATION OF THE RESPONSIBILITY OF A RESEARCH PROJECT.}

\subsection{Case study design}

\subsubsection{Identify the RRI goals of the specific project stage}

The model has been applied to ongoing research. The project aims to develop a realtime recommendation system with dynamic content based on the context of the user in mobility and their social networks to reduce the human interaction with the mobile device and improve the user's experience. The system is a novel Information and Communication Technologies (ICT) application aimed at encouraging consumption in smart cities based on consumer preferences. Allowing local businesses to offer personalized products and services in real time through an app in the beneficiaries' smartphones.

This project is currently in an early stage (phase 1 of 9 ) of development. The six key areas of RRI were reviewed and, based on the researchers' experience, they were all selected for the research. They found challenges to be correctly anticipated in all the six areas.

\subsubsection{Analyse the Project context and define the procedure}

In this case the project is developed in order to improve the tourist experience and support local businesses for a city. It consists of the following phases:

1. Analysis, requirements and specifications of information consumption regarding mobility: The purposes of this first phase are to identify, describe and specify the most relevant requirements of end users, stakeholders and technology, at a detailed level to inform and guide the research project and development work on subsequent phases.

2. User profiles and clustering: This phase focuses on the storage of large amounts of data, a variety of information sources, and high capacity data processing and modelling.

3. Cognitive processes of the user: The main objective here is to offer a comprehensive understanding of the different clusters of potential end-users of the platform and their needs.

4. Tools for the analysis and semantic management of conversations in Social Networks: The main objective of this phase is to provide the methods for semantic analysis of conversations on social networks.

5. Real-time recommendation systems: This phase addresses creating a realtime advisory system based on the management and exploitation of information in the context of mobile users and social media participation. 
6. Mobile app: Here, a robust mobile application is developed for the purposes of the research.

7. Validation and evaluation: The aim of this phase is to carry out a user-centred design process throughout the project, involving the end user in all phases of the project.

The project is currently in its first phase, developed by a multidisciplinary team from a local University, a Local Tourist Office and several firms in the private sector.

\subsubsection{Identify Experts}

Three experts have been selected for the procedure, representing different approaches to the problem. Expert 1 is a project manager; a person with an engineering background with years of experience in management of research projects. Management ranging from technical issues of small projects to complex management of multiyear big projects with dozens of human resources, hundreds of thousands of Euros budget, several scientific disciplines involved, etc.

Expert 2 is an RRI researcher. This person started in Corporate Social Responsibility and in the last 5 years has participated in European and national projects about RRI and how to operationalize it. Expert 2 has experience the analysis of RRI in both publicly and privately funded research and innovation projects

Expert 3 has a wide experience in stakeholder participation, multicriteria decision making and negotiation methods. Expert 2 usually participates in great scope projects with complex interaction with different stakeholders that produce important social, environmental and economic impacts, both positive and negative.

In ANP, due to the kind of information available, the quality of experts is more important than the number of them, as discussed in [Referencia al paper de Antonella: An AHP-Topsis Integrated Model for Selecting the Most Appropriate Tomography Equipment, el que nos pide el reviewer 2]. To be considered an appropriate expert for the research, requisites were: broad experience on the issue, to belong to a specific category of key actors of the problem: expert on research projects, RRI expert, or stakeholder expert. and willingness to learn the procedure. Only the above listed experts fulfilled all the requirements. Unfortunately, other experts who could have enriched the outcomes were not available or not suitable. In order to prevent biasing the results, only one expert per approach was selected.

\subsection{Modelling the ANP Model}

The first step to build the ANP model is to determine the main goal. In this case it is "To assess how much stakeholders contribute to the anticipation of the responsibility of the project and the exploitation of its outcomes in a context of RRI". Afterwards the elements of the model were identified (section 3.2.1 and 3.2.2). The authors of this paper acted as ANP facilitators. 


\subsubsection{Identification of stakeholders}

Stakeholders are considered the first cluster of elements in the ANP model. They represent the elements that will be evaluated. A first list of stakeholders was developed based on a literature review. An initial list was elaborated with 14 stakeholders.

Later, a panel of interested actors was arranged to discuss the list of stakeholders based on the project activities and expected outcomes, the experience of the members of the project consortium, and the early stage at which the project stands currently. The panel was formed by the ANP experts, the authors of the paper and selected members of the project consortium. 7 of the former stakeholders were discarded as "not influential now": "Media", "Regional government", "Suppliers", "Labour unions", "Competitors", "Law institutions" and "Owners of the business or partners in the consortium".

Finally, of the seven stakeholders in the list, "Neighbourhood associations" (they are directly affected or benefited by tourism) and "NGO's" (interested in the socialenvironmental impacts of tourism) were also discarded. They were found to be much less influential than the other five for this specific project at this current stage, and it was not necessary to assess them.

Hence, five stakeholders were finally added to the ANP model:

- S1. Users: they are beneficiaries of the project. Anyone who is or could be interested in the city's offer. Mainly: Tourists, visitors or residents. The main interest of this group in the project is in the services of the final results, the app for smartphones.

- S2. Business: they are also beneficiaries. Anyone who offers an activity of leisure or entertainment in the city, e.g., restaurants, museums, hotels, mobility and transportation, concerts, events, exhibitions, etc. Their main interest is to improve the communication of their offer of products and services.

- S3. Local Tourism Office (LTO): It takes the role of the stakeholder "policy maker". In this case, the policy maker would be the LTO, which is the most relevant authority in terms of tourism management. Its main interest is contributing to the tourist development of the city.

- S4. Developers: It takes the role of the stakeholder "employees". The group that creates and designs all the digital content. They are the intermediators between users' preferences and business offer.

- S5. The National Ministry of Economy: It takes the role of "funders" It provides the economic resources and demands to meet the goals, deadlines and quality requirements of the project. 


\subsubsection{Identification of criteria and clusters}

The rest of the network elements are the criteria which could evaluate the influence of stakeholders in the project responsibility. Elements that have a general character to evaluate influence in terms of RRI were identified at the cluster level. Each of them was further divided into sub-elements (criteria). According to the method followed in other AHP/ANP applications (Saaty 2001; Sipahi and Timor 2010)

An initial list of criteria for each cluster was defined based on a literature review (Claudia et al. 2014; Rosso et al. 2014; Strand et al. 2015; Aragonés-Beltrán et al. 2017; Lubberink et al. 2017; RRI-TOOLS project). It was necessary to make sure that these criteria were relevant and not redundant (Saaty 1990; Yüksel and Dagdeviren 2007; Görener 2012). With the assistance of the experts, the final criteria list was obtained. Experts established the definition and the purpose of each criterion, making sure that each expert understood them. The final list has 16 criteria grouped in three clusters (Table 1).

Table 1. Evaluation criteria

\begin{tabular}{|c|c|c|c|}
\hline Cluster & Definition & Criteria & Definition \\
\hline \multirow{8}{*}{$\begin{array}{l}\text { C1. } \\
\text { Knowledge } \\
\text { of RRI } \\
\text { areas }\end{array}$} & \multirow{8}{*}{$\begin{array}{l}\text { Criteria aimed at } \\
\text { assessing } \\
\text { stakeholders' } \\
\text { knowledge of RRI } \\
\text { concepts. } \\
\text { In general this is a } \\
\text { weak point, since there } \\
\text { is a general lack of } \\
\text { knowledge of the topic, } \\
\text { which implies the need } \\
\text { to inform the } \\
\text { stakeholders about the } \\
\text { most basic concepts of } \\
\text { responsibility. }\end{array}$} & $\begin{array}{l}\text { C1.1 Public } \\
\text { engagement }\end{array}$ & $\begin{array}{l}\text { It refers to the societal commitment to provide } \\
\text { encouragement, opportunities and competences in } \\
\text { order to empower citizens to participate in debates } \\
\text { around R \& I, with potential feedback and feed- } \\
\text { forward for the scientific process. }\end{array}$ \\
\hline & & C1.2 Gender equality & $\begin{array}{l}\text { Promotes the equal participation of men and } \\
\text { women in research activities and the inclusion and } \\
\text { integration of gender perspectives in } R \text { \& I content }\end{array}$ \\
\hline & & $\begin{array}{l}\text { C1.3 Science } \\
\text { education }\end{array}$ & $\begin{array}{l}\text { The need to enhance the current education process } \\
\text { to better equip future researchers and other societa } \\
\text { actors with the necessary knowledge and tools to } \\
\text { fully participate and take responsibility in the } \\
\text { research and innovation process. }\end{array}$ \\
\hline & & C1.4 Ethics & $\begin{array}{l}\text { Related to research integrity and good research } \\
\text { practice, the protection of the objects of research } \\
\text { and, the societal relevance and ethical acceptability } \\
\text { of R \& I outcomes. }\end{array}$ \\
\hline & & C1.5 Governance & $\begin{array}{l}\text { Any form of coordination designed to foster and } \\
\text { mainstream RRI within an organization or in the } \\
\text { interaction with other stakeholders }\end{array}$ \\
\hline & & C1.6 Open access & $\begin{array}{l}\text { Practice in which the scientific process is shared } \\
\text { completely and in real time. }\end{array}$ \\
\hline & & C1.7 Sustainability & $\begin{array}{l}\text { Evaluates to what extent a research field, } \\
\text { research program or an } \mathrm{RRI} \text { initiative contributes to } \\
\text { sustainable growth. }\end{array}$ \\
\hline & & C1.8 Social justice & $\begin{array}{l}\text { Impact of research and its effect on socia } \\
\text { justice/inclusion. Considered from the relationship } \\
\text { between the researchers and the research } \\
\text { subjects; and the participation of social groups in } \\
\text { benefits arising from research. }\end{array}$ \\
\hline
\end{tabular}




\begin{tabular}{|c|c|c|c|}
\hline Cluster & Definition & Criteria & Definition \\
\hline \multirow{4}{*}{$\begin{array}{l}\text { C2. } \\
\text { Diffusion }\end{array}$} & \multirow{4}{*}{$\begin{array}{c}\text { Refers to some } \\
\text { attributes that allow } \\
\text { stakeholders to engage } \\
\text { in the dialogue and } \\
\text { spread the project, to } \\
\text { generate debates and } \\
\text { networking and to } \\
\text { identify relevant } \\
\text { aspects. }\end{array}$} & C2.1 Transversality & $\begin{array}{l}\text { It refers to the diversity of stakeholders, to how } \\
\text { complex it is. }\end{array}$ \\
\hline & & C2.2 Group size & $\begin{array}{l}\text { The number of members in society of a } \\
\text { stakeholder. }\end{array}$ \\
\hline & & C2.3 Activism & How active, critical or proactive a stakeholder is. \\
\hline & & $\begin{array}{l}\text { C2.4 Relations with } \\
\text { the project }\end{array}$ & $\begin{array}{l}\text { Evaluates how the relationships between the } \\
\text { project consortium and the stakeholders are. It } \\
\text { takes into account previous relationships. }\end{array}$ \\
\hline \multirow{4}{*}{$\begin{array}{c}\text { C3. } \\
\text { Possible } \\
\text { resources } \\
\text { providers }\end{array}$} & \multirow{4}{*}{$\begin{array}{l}\text { Refers to the } \\
\text { willingness and } \\
\text { capability of one } \\
\text { stakeholder to provide } \\
\text { the project with } \\
\text { resources. }\end{array}$} & C3.1 Financial & $\begin{array}{l}\text { How much a stakeholder can contribute with } \\
\text { financial resources to anticipate the project } \\
\text { responsibility. }\end{array}$ \\
\hline & & C3.2 Communication & $\begin{array}{l}\text { How much a stakeholder can spread out and } \\
\text { communicate the project to help achieve the } \\
\text { desired anticipation. }\end{array}$ \\
\hline & & C3.3 Personal & $\begin{array}{l}\text { How much a stakeholder can contribute with human } \\
\text { resources to anticipate the project responsibility. }\end{array}$ \\
\hline & & C3.4 Hard-data & $\begin{array}{l}\text { How much a stakeholder can contribute with } \\
\text { reliable and accurate data to help to anticipate the } \\
\text { project more responsibility }\end{array}$ \\
\hline
\end{tabular}

\subsubsection{Establishing ANP structure}

After the identification of the elements, dependencies among them were determined by experts using a relationship matrix, where one (1) means that the element of the column depends on the element of the row, and cero (0) means that there is no dependence among them (Table 2). Dependence of $A$ on $B$, as explained, means $B$ influences $A$ as regards the ANP goal, i.e. $B$ influences $A$ for the assessment of how much a stakeholder contributes to the anticipation or RRI issues of the project. For example, cell a12 $=1$ means the element 1.2 . Gender equality is influenced by the element 1.1. Public engagement for the assessment. And experts considered that on the grounds that for identifying gender inequality issues public engagement is needed. But the contrary was found to be true too, element 1.1 is influenced by element 1.2 and experts filled cell a21 $=1$. That is so because they consider that if there is gender inequality the public will more easily get engaged in the debate about the desirability of the projects and their outcomes, and go beyond the specific gender issues.

Table 2. Dependence matrix of all elements of the model

\begin{tabular}{|c|cccccccc|cccc|cccc|ccccc|}
\hline & 1.1 & 1.2 & 1.3 & 1.4 & 1.5 & 1.6 & 1.7 & 1.8 & 2.1 & 2.2 & 2.3 & 2.4 & 3.1 & 3.2 & 3.3 & 3.4 & S1 & S2 & S3 & S4 & S5 \\
\hline 1.1 & & 1 & 1 & 1 & 1 & 1 & 1 & 1 & 1 & 1 & 1 & 1 & 0 & 1 & 0 & 1 & 1 & 1 & 1 & 1 & 1 \\
1.2 & 1 & & 0 & 0 & 1 & 0 & 0 & 1 & 1 & 0 & 1 & 0 & 0 & 0 & 0 & 0 & 1 & 1 & 1 & 1 & 1 \\
1.3 & 1 & 0 & & 0 & 0 & 0 & 0 & 1 & 1 & 0 & 1 & 0 & 0 & 1 & 0 & 0 & 1 & 1 & 1 & 1 & 1 \\
1.4 & 0 & 0 & 0 & & 0 & 0 & 1 & 1 & 0 & 0 & 0 & 1 & 0 & 0 & 0 & 1 & 1 & 1 & 1 & 1 & 1 \\
1.5 & 1 & 0 & 0 & 1 & & 1 & 1 & 1 & 0 & 0 & 1 & 0 & 0 & 0 & 0 & 0 & 1 & 1 & 1 & 1 & 1 \\
1.6 & 0 & 0 & 1 & 0 & 0 & & 0 & 1 & 0 & 0 & 0 & 0 & 0 & 1 & 0 & 1 & 1 & 1 & 1 & 1 & 1 \\
1.7 & 1 & 0 & 0 & 1 & 0 & 0 & & 1 & 0 & 0 & 0 & 0 & 0 & 0 & 0 & 0 & 1 & 1 & 1 & 1 & 1 \\
1.8 & 1 & 1 & 0 & 0 & 0 & 1 & 1 & & 1 & 1 & 1 & 0 & 0 & 0 & 0 & 0 & 1 & 1 & 1 & 1 & 1 \\
\hline 2.1 & 0 & 0 & 0 & 0 & 0 & 0 & 0 & 0 & & 1 & 1 & 1 & 0 & 1 & 0 & 1 & 1 & 1 & 1 & 1 & 1 \\
2.2 & 0 & 0 & 0 & 0 & 0 & 0 & 0 & 0 & 0 & & 0 & 1 & 0 & 1 & 0 & 1 & 1 & 1 & 1 & 1 & 1
\end{tabular}




\begin{tabular}{|l|llllllll|lllll|llll|lllll|}
2.3 & 0 & 0 & 0 & 0 & 0 & 0 & 0 & 0 & 0 & 0 & & 1 & 0 & 1 & 0 & 1 & 1 & 1 & 1 & 1 & 1 \\
2.4 & 0 & 0 & 0 & 0 & 0 & 0 & 0 & 0 & 0 & 0 & 0 & & 1 & 1 & 1 & 1 & 1 & 1 & 1 & 1 & 1 \\
\hline 3.1 & 0 & 0 & 0 & 0 & 0 & 0 & 0 & 0 & 0 & 0 & 0 & 1 & & 1 & 1 & 1 & 1 & 1 & 1 & 1 & 1 \\
3.2 & 0 & 0 & 0 & 0 & 0 & 0 & 0 & 0 & 0 & 0 & 0 & 1 & 0 & & 0 & 1 & 1 & 1 & 1 & 1 & 1 \\
3.3 & 0 & 0 & 0 & 0 & 0 & 0 & 0 & 0 & 0 & 0 & 0 & 1 & 0 & 0 & & 0 & 1 & 1 & 1 & 1 & 1 \\
3.4 & 0 & 0 & 0 & 0 & 0 & 0 & 0 & 0 & 0 & 0 & 0 & 1 & 0 & 1 & 0 & & 1 & 1 & 1 & 1 & 1 \\
\hline S1 & 1 & 1 & 1 & 1 & 1 & 1 & 1 & 1 & 1 & 1 & 1 & 1 & 1 & 1 & 1 & 1 & & 1 & 1 & 1 & 1 \\
S2 & 1 & 1 & 1 & 1 & 1 & 1 & 1 & 1 & 1 & 1 & 1 & 1 & 1 & 1 & 1 & 1 & 1 & & 1 & 1 & 1 \\
S3 & 1 & 1 & 1 & 1 & 1 & 1 & 1 & 1 & 1 & 1 & 1 & 1 & 1 & 1 & 1 & 1 & 1 & 1 & & 1 & 1 \\
S4 & 1 & 1 & 1 & 1 & 1 & 1 & 1 & 1 & 1 & 1 & 1 & 1 & 1 & 1 & 1 & 1 & 1 & 1 & 1 & & 1 \\
S5 & 1 & 1 & 1 & 1 & 1 & 1 & 1 & 1 & 1 & 1 & 1 & 1 & 1 & 1 & 1 & 1 & 1 & 1 & 1 & 1 & \\
\hline
\end{tabular}

The proposed model is illustrated by the network shown in Figure 2. The arrows indicate dependencies between clusters. That is to say, the elements in a cluster (i) exert some influence over elements in another cluster (j). Feedback arrows mean that there are influences among criteria belonging to the same cluster. Bidirectional arrows indicate influences in both directions.

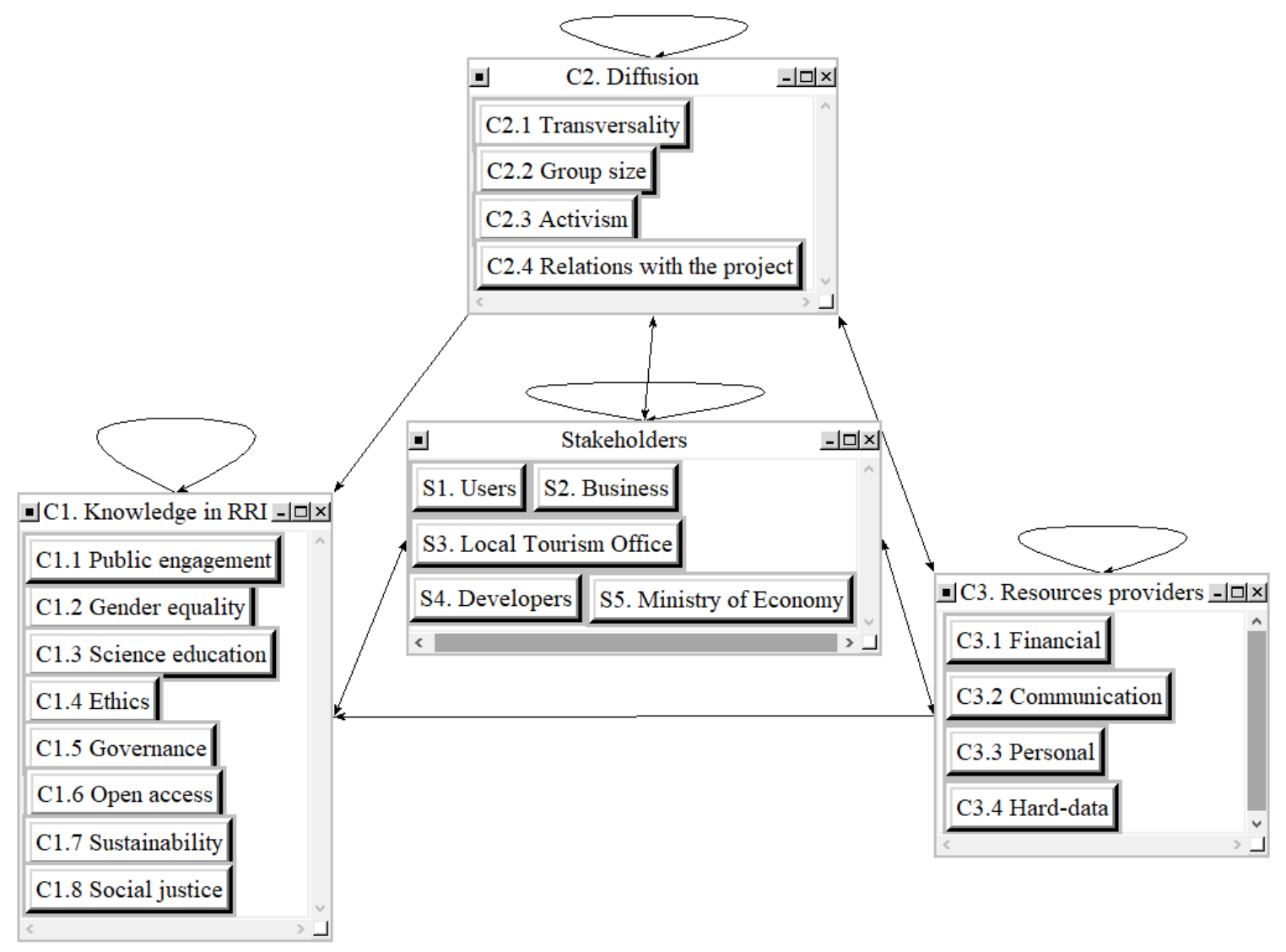

Figure 2. ANP network model of the case study.

\subsection{Assessing stakeholders' influence by means of ANP}

Once the model was agreed upon, the ANP questionnaire was designed with the aim of determining a relative importance for each stakeholder with regard to all the 
considered criteria. That is to say, how much each stakeholder can contribute to the anticipation of the responsibility of the project. The required judgements were collected from the experts through a questionnaire designed with pairwise comparisons. Figure 3 shows an example of one of the questions.

\begin{tabular}{|l|l|lllll|l|lllll|l|}
\hline \multicolumn{1}{|c|}{ In your opinion, which of the two criteria influence more on the criteria C1.1 Public engagement? } \\
Place an X where appropriate. \\
\hline \\
\end{tabular}

Figure 3. Example of a question used for the ANP questionnaire

All the calculations were performed using the Superdecision@ v.2.0.8. software. Once experts finished all pairwise comparisons, a limit supermatrix per expert was obtained.

The final limit matrix has the same values in all the columns. It shows the weight obtained for each element, a non-dimensional value that can be considered as their relative importance as regards the ANP goal. These values were normalized (by multiplying them by a constant that is the reciprocal of their sum (Saaty 1990)) to obtain the final results. Care was taken to ensure that all pairwise comparison matrices had a consistency ratio (CR) of less than $10 \%$, as required by the method.

Since 3 experts were interviewed, 3 individual results were obtained. Each one shows the relative importance according to their judgments. Aggregation of Individual Judgments (AIJ) was performed in order to obtain a global judgement for all the experts, that is to say, a new limit supermatrix with the aggregation by means of the geometric mean of the judgments of the three experts. Then another final limit matrix was calculated showing the aggregated preferences of the experts.

\section{DISCUSSION OF RESULTS}

In order to present the results, three different analyses have been carried out. First, the weights of the clusters have been obtained and compared both for the individuals and for the group. Secondly, criteria have also been analysed for the individuals and for the group. Thirdly, the ranking of the analysed stakeholders has been obtained, which is the final aim of this whole evaluation process. 


\subsection{At the cluster level}

The cluster weighting provides some important insights into the overall perspective and underlying participants' conception of how the project consortium could involve stakeholders in responsible research. Individual preferences show that Expert 1 and Expert 3 give the highest importance to C2.Diffussion (Table 3 and Figure 4). This means that in order to anticipate the RRI issues of the project, these experts consider it to be more important to take advantage of the stakeholders' potential to spread out the project engaging people in the debate. While for Expert 2 C1. Knowledge of RRI areas is clearly more important than any other characteristic or resources that a stakeholder might have.

The aggregated result shows more balanced weights, as usual. The most important clusters are C2. Diffusion $(0,341)$ and C1. Knowledge in RRI Areas $(0,316)$. In a second level C3. Resources $(0,144)$ would be classified.

Table 3. Results obtained for the clusters

\begin{tabular}{|l|c|c|c|c|}
\hline \multicolumn{1}{|c|}{ Cluster } & Expert 1 & Expert 2 & Expert 3 & Aggregation \\
\hline C1. RRI Areas & 0,0965 & 0,6884 & 0,1645 & 0,2698 \\
\hline C2. Diffusion & 0,4094 & 0,1816 & 0,4330 & 0,3868 \\
\hline C3. Resources & 0,2895 & 0,0501 & 0,0939 & 0,1348 \\
\hline Stakeholders & 0,2047 & 0,0799 & 0,3085 & 0,2086 \\
\hline
\end{tabular}

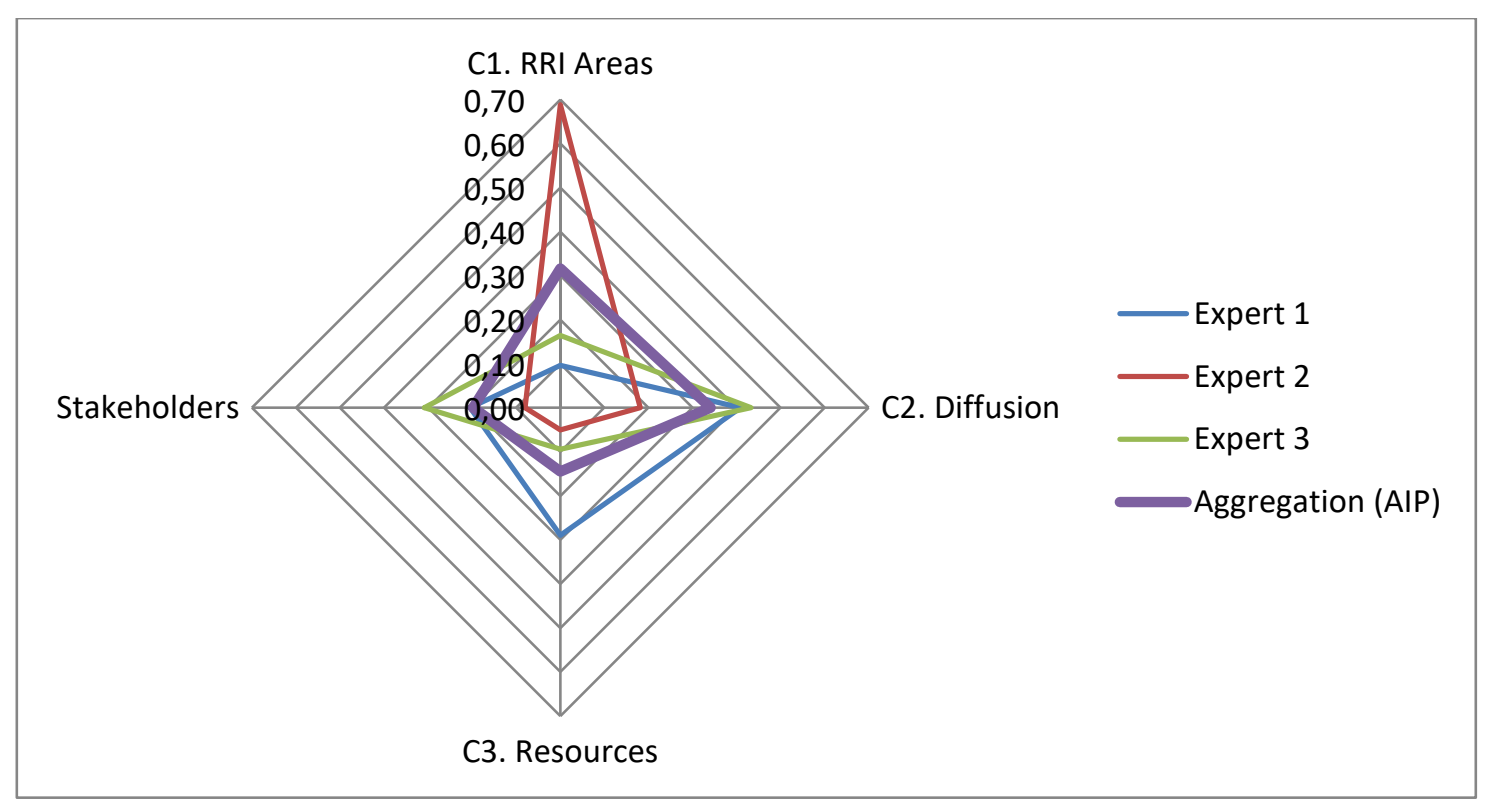

Figure 4. Cluster results according to experts, and aggregated results. 


\subsection{At the criteria level}

Regarding these results the main conclusion is that the most relevant criterion is $C 1.1$ Public engagement (Table 4). In fact, it is the first criterion for Experts 2 and 3, and the second most important for Expert 1. Following in importance we obtain a group of criteria formed by, C1.8 Social Justice, C2.4 Relations with the project and C2.1 Transversality. Expert 2 shows different preferences compared with Experts 1 and 3 , who show more similar profiles.

The most important criteria after C2.4 Relations with the project for Expert 1 are $C 1.1$ Public engagement, and C2.1. Transversality. For expert 2 there are two main criteria: C1.1 Public engagement and then C1.8 Social justice, the others fall clearly behind. Finally, Expert 3 considers as does Expert 1 that C2.4 Relations with the project is most influential, then C1.1 Public engagement, and then C2.1. Transversality.

Table 4. Results obtained for the criteria

\begin{tabular}{|l|c|c|c|c|}
\hline \multicolumn{1}{|c|}{ Criteria } & Expert 1 & Expert 2 & Expert 3 & Aggregation \\
\hline C1.1 Public engagement & 0,115 & 0,230 & 0,115 & 0,152 \\
\hline C1.2 Gender equality & 0,034 & 0,107 & 0,062 & 0,068 \\
\hline C1.3 Science education & 0,073 & 0,060 & 0,024 & 0,052 \\
\hline C1.4 Ethics & 0,022 & 0,079 & 0,040 & 0,047 \\
\hline C1.5 Governance & 0,039 & 0,101 & 0,078 & 0,073 \\
\hline C1.6 Open access & 0,046 & 0,022 & 0,026 & 0,031 \\
\hline C1.7 Sustainability & 0,012 & 0,057 & 0,030 & 0,033 \\
\hline C1.8 Social justice & 0,059 & 0,171 & 0,099 & 0,110 \\
\hline C2.1 Transversality & 0,113 & 0,060 & 0,113 & 0,095 \\
\hline C2.2 Group size & 0,037 & 0,014 & 0,065 & 0,039 \\
\hline C2.3 Activism & 0,101 & 0,025 & 0,084 & 0,070 \\
\hline C2.4 Relations with the project & 0,129 & 0,033 & 0,148 & 0,103 \\
\hline C3.1 Financial & 0,087 & 0,009 & 0,042 & 0,046 \\
\hline C3.2 Communication & 0,055 & 0,017 & 0,014 & 0,029 \\
\hline C3.3 Personal & 0,027 & 0,006 & 0,024 & 0,019 \\
\hline C3.4 Hard-data & 0,051 & 0,012 & 0,037 & 0,033 \\
\hline
\end{tabular}

Global results of table 3 are shown in Figure 5 for clarity. As can be seen, after the highlighted criteria: C1.1., C1.8., C2.4 and C2.1, follows a group of criteria formed by C1.5 Governance, C2.3 Activism and C1.2 Gender equality with an importance of between 6 and 8\%. The least important criteria are: C3.4 Hard-data, C1.7 Sustainability, C1.6 Open access, C3.2 Communication and C3.3 Personal, that have an importance of $3 \%$ or less. In general, as introduced, criteria of cluster 3 Resources are less valued for the anticipation of the responsibility of the project. 


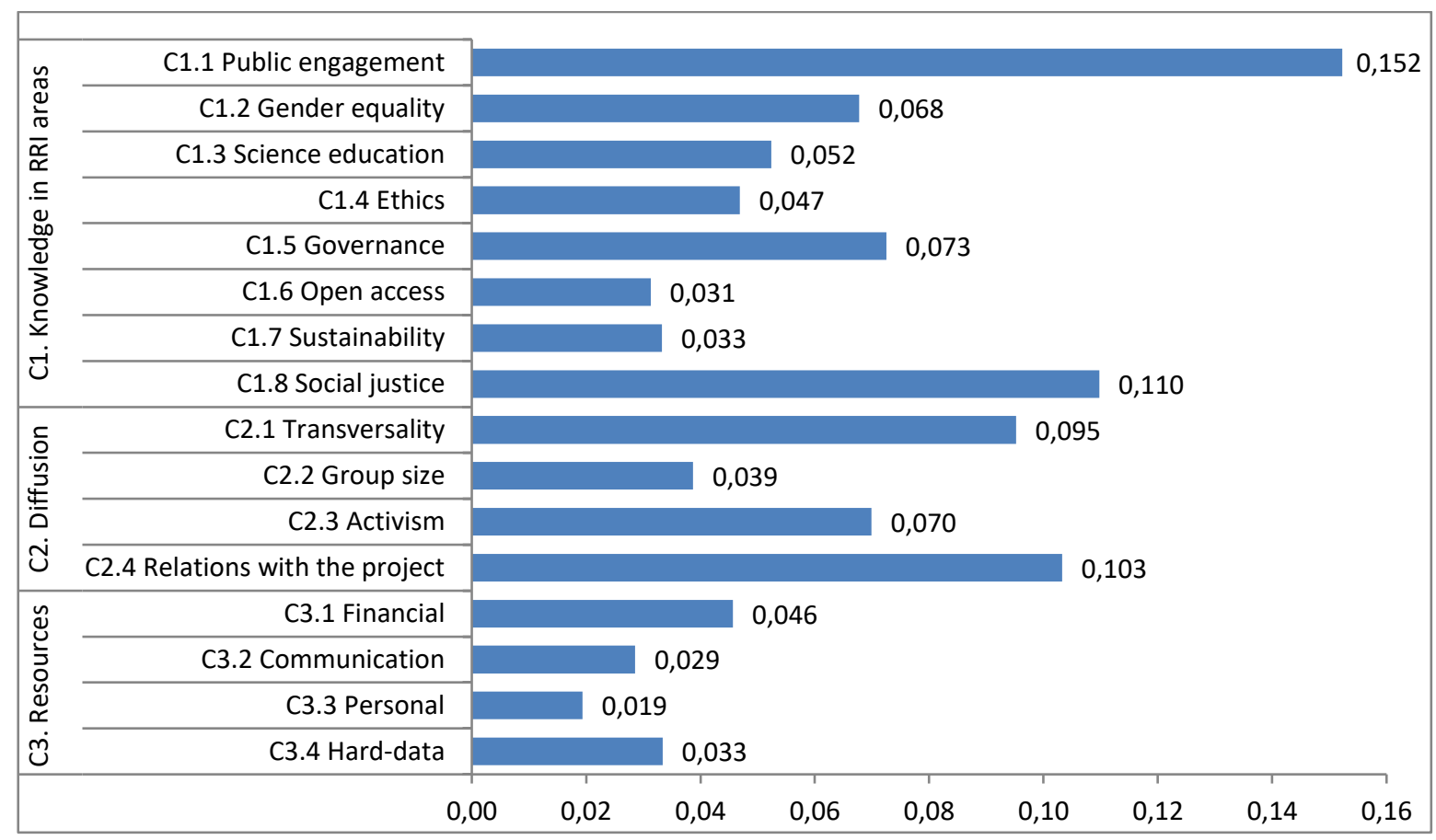

Figure 5: Results for the criteria.

To end with the discussion of the results for assessment criteria, the case under study has specific characteristics that, together with those of the consortium members, have shaped the most important features to select the influential stakeholders. That criteria related to stakeholder competence and willingness to debate, and their closeness to the research members, are so influential, which does not mean that features like stakeholder group size, activism or possibility to add their own resources to the anticipation of RRI issues may not be more valued by other research teams in other projects, at other development stages.

\subsection{Stakeholder influence}

An overall preference for each stakeholder with regard to all the considered criteria has been obtained. It assesses the relative importance of each stakeholder with regards to the ANP goal. Therefore, the higher the preference, the more influential the stakeholder is. Table 5 show the values of the final limit matrixes and the normalised values. As can be seen, on average the most influential stakeholders are: S4. Developers $(24,8 \%$ of the total weight), S5. Financial support $(23,1 \%)$ and S3. Local administration (21,8\%). In a second group fall S1.Users $(18,6 \%)$ and S2. Business $(11,6 \%)$.

Table 5. Limited and Normalized values for the stakeholders

\begin{tabular}{|l|l|c|c|c|c|c|c|c|c|}
\hline & & \multicolumn{2}{c|}{ Expert 1 } & \multicolumn{2}{c|}{ Expert 2 } & \multicolumn{2}{c|}{ Expert 3 } & \multicolumn{2}{c|}{ Aggregated } \\
\hline & & Limit & $\begin{array}{l}\text { Norm } \\
\text { alized }\end{array}$ & Limit & $\begin{array}{l}\text { Norm } \\
\text { alized }\end{array}$ & Limit & $\begin{array}{l}\text { Norm } \\
\text { alized }\end{array}$ & Limit & $\begin{array}{c}\text { Norm } \\
\text { alized }\end{array}$ \\
\hline \multirow{2}{*}{} & S1. Users & 0,052 & 0,151 & 0,068 & 0,176 & 0,079 & 0,231 & 0,065 & 0,186 \\
\hline
\end{tabular}




\begin{tabular}{|l|l|c|c|c|c|c|c|c|c|}
\hline & 0,037 & 0,106 & 0,062 & 0,162 & 0,028 & 0,081 & 0,040 & 0,113 \\
\hline S2. Business & 0,077 & 0,223 & 0,090 & 0,233 & 0,068 & 0,198 & 0,078 & 0,220 \\
\hline S3. Local Tourism Office & 0,092 & 0,267 & 0,075 & 0,194 & 0,097 & 0,283 & 0,087 & 0,248 \\
\hline $\begin{array}{l}\text { S4. Developers } \\
\text { S5. The National Ministry of } \\
\text { Economy }\end{array}$ & 0,087 & 0,252 & 0,090 & 0,234 & 0,071 & 0,208 & 0,082 & 0,233 \\
\hline & $\mathbf{0 , 3 4 5}$ & $\mathbf{1 , 0 0 0}$ & $\mathbf{0 , 3 8 5}$ & $\mathbf{1 , 0 0 0}$ & $\mathbf{0 , 3 4 3}$ & $\mathbf{1 , 0 0 0}$ & $\mathbf{0 , 3 5 3}$ & $\mathbf{1 , 0 0 0}$ \\
\hline
\end{tabular}

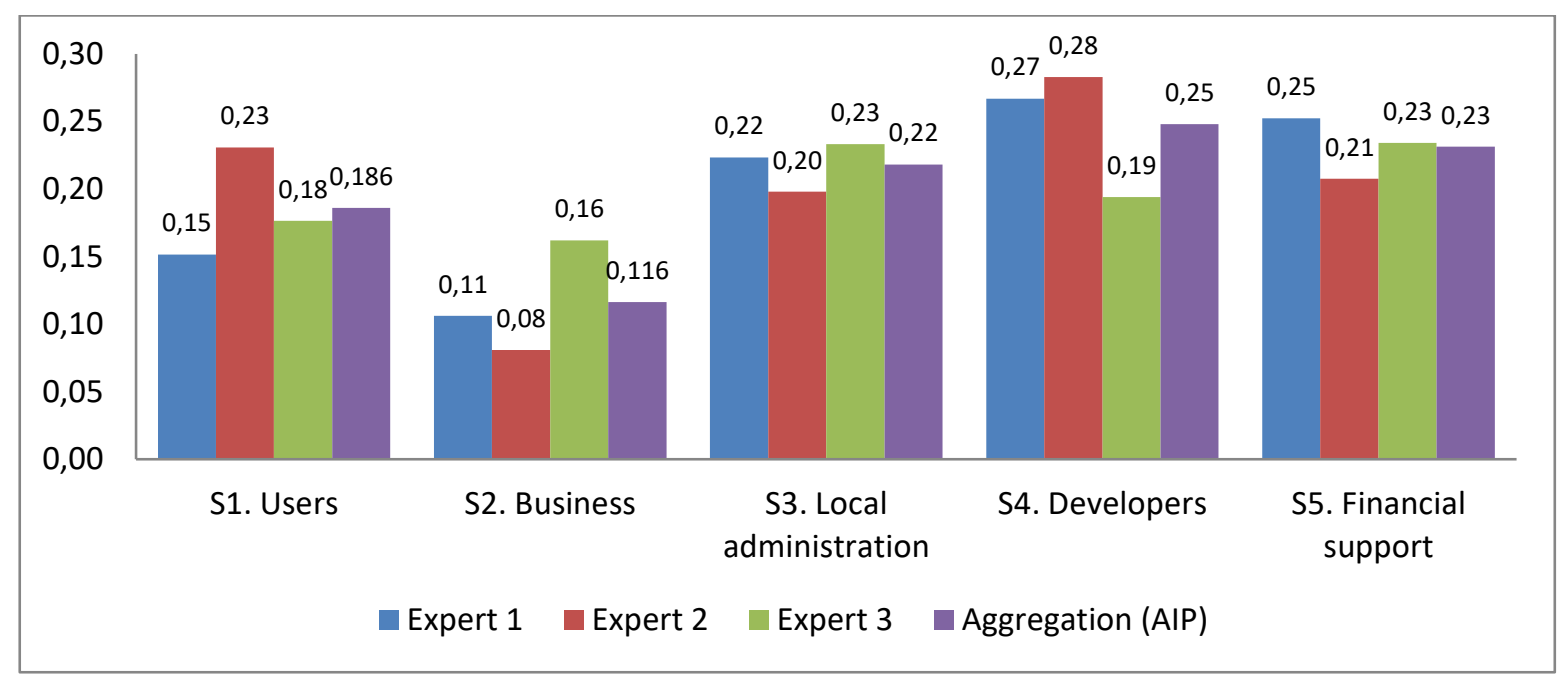

Figure 6: Results for the stakeholders

The results also allow us to analyse the experts' individual preferences. Based on the obtained results (Table 5, Figure 6), the different experts show some differences in the ranking order of the five stakeholders. For expert 1 the ranking order of stakeholders would distinguish S4 Developers, S5 The National Ministry of Economy, and S3 Local Tourism Office from the rest. For expert 2 only S5 The National Ministry of Economy and S3 Local Tourism Office would be highlighted. And for Expert 3, only S4 Developers and S1 Users would be the most preferred.

The results, besides, allow us to differentiate groups of stakeholders based on their importance. This differentiation is qualitative and open to different interpretations, and here the decision of the project consortium members is shown. Based on the procedure and its learning, and also looking at the differences among stakeholders' final ANP values, three groups were made. It is important to mention that all stakeholders of this classification are influential and ought to be managed. But in a situation of limited resources and some reluctance of the stakeholders to tackle the challenge of RRI, it is advisable to devote more resources: time, people, effort, money, etc. to the most influential ones. And hence the interest to classify them.

The first group was called the most influential one (S4 Developers, S5 The National Ministry of Economy, and S3 Local Tourism Office) including those who, according to the experts' judgments are the stakeholders who can contribute more to the 
anticipation of the responsibility of the project. Therefore, they should be the ones who the consortium should focus on managing.

The second group (S1 Users) is called just influential, as they are less clearly preferred at that moment for the RRI analysis. However, Users are key to the project and involved in the research itself in the user-centred design. In fact, their influence on the $\mathrm{RRI}$ issues may change as the project evolves into a new phase where the procedure of the application will be further developed and, for example data privacy, offers discrimination, environmental information, or other project decisions will be more relevant. Also, the ranking of stakeholders, or the inclusion of new ones, may be needed as the team follows the RRI self-learning process and moves on to Reflection, Deliberation or Responsiveness (Stilgoe et al. 2013).

Finally, (S2 Business), are the least preferred among the influential at the moment. The experts have found the other stakeholders to be preferred for debating the responsibility of the research at its current development phase. Later, when the detailed determination of the app contents demands from Users and Business a closer participation, their role in the responsibility of the project is expected to be clearly more influential.

ANP also allows us to analyse why some of the alternatives are preferred to others. In this case, this analysis shows those stakeholders to be more influential on C1.1. Public Engagement, C1.8. Social Justice and C2.4. Relations with the project, obtained the higher values.

\section{CONCLUSIONS}

In this paper we have provided a novel application of an MCDM technique to evaluate the stakeholder influences on a project, which in this case is applied to their contribution to the anticipation of the responsibility of the project and its possible outcomes. By means of the model the global concept of influence is broken down into sixteen criteria, evaluating different aspects that together enable us to define a preference. The preference measures the greater or lesser influence of stakeholders on research responsibility within a framework of RRI. Thus, they can prioritize based on their expected contribution to the anticipation of the issues related to the social desirability of the activity.

Stakeholder management is normally a key activity in research, and particularly so in responsible research. Within stakeholder management, stakeholder analysis is critical for identifying, understanding and proposing strategies for involving them as much as decided. The existing methods of stakeholder analysis can be complemented with the results of the investigation herein presented. The ANP method has shown useful to rank and order the stakeholders, a purpose other methods do not cover, or address 
very indirectly. Besides, ANP can be adopted and applied to other types of influence assessment.

According to the RRI perspective, as the project develops, a more inclusive stakeholder dialogue will be necessary, including a broader spectrum of stakeholders. For example, in this case study, experts discarded firstly listed stakeholders like $S 7$ Neighbourhood associations (they are directly affected or benefited by tourism) and S6 NGO's (interested in the social-environmental impacts of tourism). However, those stakeholders can vary their influence later in the project's development. Or in a following stage of the team's RRI self-learning process: Reflection, Deliberation or Responsiveness.

As regards the results of the case study, the ANP goal was to assess how much stakeholders contribute to the anticipation of the responsibility of the project and the exploitation of its outcomes. Based on that, Expert 1 the project manager and Expert 3 the stakeholder manager give similar evaluations to criteria, highlighting the criterion C2.4. Relations with the project, and C1.1. Public engagement. While Expert 2, the $\mathrm{RRI}$ researcher, does not give importance to C2.4., gives importance to C1.1., and gives importance to $\mathrm{C} 1.8$. Social justice itself is not really considered by the other experts. The aggregation of the experts' judgments leads to the assignment of the highest importance to criterion C1.1., followed by C1.8. and C2.4. And the least importance to C3.3. Personal and C1.6. Open access.

The most influential stakeholder of the case study evaluated is "S4 Developers", based on the ANP goal. For the experts and the paper authors this is understandable as, considering the early stage the project is in, and going through Anticipation in the selflearning process of the project consortium, this stakeholder is key in the usability, inclusivity, energy consumption and other features that will make the greatest socialenvironmental impacts, should the project be finally carried out, and its foreseen app become a success.

The selected experts have found those stakeholders best related to the project, and more able to engage the public in a debate about the project's RRI issues. They are indeed the ones that can contribute the most to the anticipation of those issues.

As recommended by the developer of ANP, once the results are obtained a sensitivity analysis should be carried out in order to demonstrate the robustness of the ranking obtained, particularly in case some alternatives achieve very similar results. This was the case of this paper, although the sensitivity analysis only gives changes in the order of ANP elements within the identified groups, i.e. the classification of criteria or stakeholders based on their influence. Therefore, the groups of most and least influential criteria and alternatives have the same components, all through the sensitivity analysis. 


\section{Acknowledgement}

The authors would like to thank to our anonymous referees for their constructive comments and suggestions that helped us to improve the quality of the paper.

Also to the "Bolívar Gana con Ciencia" project from the Gobernación de Bolívar (Colombia) for the financial support.

For the same reason, the authors are grateful to to the Spanish Agencia Estatal de Investigación for its support of the project Propuesta de Indicadores para Impulsar el Diseño de Una Política Orientada al Desarrollo de Investigación e Innovación Responsable en España (CSO2016-76828-R).

\section{References}

Akbari N, Irawan CA, Jones DF, Menachof D (2017) A multi-criteria port suitability assessment for developments in the offshore wind industry. Renew Energy 102:118-133. doi: 10.1016/.jenene.2016.10.035

Aragonés-Beltrán P, García-Melón M, Montesinos-Valera J (2017) How to assess stakeholders' influence in project management? A proposal based on the Analytic Network Process. Int J Proj Manag. doi: 10.1016/j.jproman.2017.01.001

Bhupendra KV, Sangle S (2017) What Drives Successful Implementation of Product Stewardship Strategy? The Role of Absorptive Capability. Corp Soc Responsib Environ Manag 24:186-198. doi: 10.1002/csr.1394

Botero C, Pereira C, Tosic M, Manjarrez G (2015) Design of an index for monitoring the environmental quality of tourist beaches from a holistic approach. Ocean Coast Manag 108:65-73. doi: 10.1016/j.ocecoaman.2014.07.017

Brugha R (2000) Stakeholder analysis: a review. Health Policy Plan 15:239-246. doi: 10.1093/heapol/15.3.239

Burget M, Bardone E, Pedaste M (2016) Definitions and Conceptual Dimensions of Responsible Research and Innovation: A Literature Review. Sci Eng Ethics 23:1-19. doi: 10.1007/s11948-016-9782-1

Colin E, Ackermann F (1998) Making Strategy: The Journey of Strategic Management. SAGE Publications Ltd, London

Dahlsrud A (2006) How Corporate Social Responsibility is De ned: an Analysis of $37 \mathrm{De}$ nitions. Corp Soc Responsib Environ Manag 13:1-13. doi: 10.1002/csr

de Jong IM, Kupper F, Broerse J (2016) Inclusive deliberation and action in emerging RRI practices: the case of neuroimaging in security management. J Responsible Innov 3:2649. doi: $10.1080 / 23299460.2015 .1137752$

De Lopez T (2001) Stakeholder management for conservation projects: a case study of Ream National Park, Cambodia. J Environ Manage 28:47-60

De Lotto R, Gazzola V, Gossenberg S, et al (2016) Proposal to Reduce Natural Risks: Analytic Network Process to Evaluate Efficiency of City Planning Strategies. Springer, Cham, pp $650-664$

European Commission (2011) DG Research workshop on Responsible Research \& Innovation in Europe

European Commission (2012) Responsible Research and Innovation. Europe's ability to respond to societal challenges. 4. doi: 10.2777/11739

Görener a (2012) Comparing AHP and ANP: An Application of Strategic Decisions Making in a Manufacturing Company. Int J Bus Soc Sci 3:194-208

Kettner C, Köppl A, Stagl S (2014) Towards an operational measurement of socio-ecological performance. WIFO Working Paper no 52

Koops BJ (2015) The concepts, approaches, and applications of responsible innovations: An introduction. In: In B. J. Koops, I. Oosterlaken, H. Romijn, T. Swierstra, J. van den Hoven 
Responsible innovation 2: Concepts, approaches, and applications (pp. 1-15). Dordrecht: Springer International Publishing, pp 1-15

Lubberink R, Blok V, Ophem J van, Omta O (2017) Lessons for responsible innovation in the business context: A systematic literature review of responsible, social and sustainable innovation practices. Sustain 9:. doi: 10.3390/su9050721

Mitchell RK, Agle BR, Wood DJ (1997) Toward a theory of stakeholder identification and salience: Defining the principle of who and what really counts. Acad Manag Rev 22:853886. doi: 10.5465/AMR.1997.9711022105

Owen R, Bessant J, Heintz M (2013) Responsible Innovation: Managing the Responsible Emergence of Science and Innovation in Society. John Wiley and Sons, Chichester, UK

Peris J, García-Melón M, Gómez-Navarro T, Calabuig C (2013) Prioritizing local agenda 21 programmes using analytic network process: A spanish case study. Sustain Dev 21:338352. doi: $10.1002 / \mathrm{sd} .514$

Ramzan N, Degenkolbe S, Witt W (2008) Evaluating and improving environmental performance of HC's recovery system: A case study of distillation unit. Chem Eng $\mathrm{J}$ 140:201-213. doi: 10.1016/j.cej.2007.09.042

Rosso M, Bottero M, Pomarico S, et al (2014) Integrating multicriteria evaluation and stakeholders analysis for assessing hydropower projects. Energy Policy 67:870-881. doi: 10.1016/j.enpol.2013.12.007

Saaty TL (2001) The Analytic Network Process: Decision Making with Dependence and Feedback. RWS Publications

Saaty TL (1990) How to make a decision: The analytic hierarchy process. Eur J Oper Res 48:9-26. doi: 10.1016/0377-2217(90)90057-I

Saaty TL (1994) How to Make a Decision: The Analytic Hierarchy Process. Interfaces (Providence). 24:19-43

Saaty TL (2005) Theory and Applications of the Analytic Network Process: Decision Making with Benefits, Opportunities, Costs, and Risks. The Analytic Hierarchy Process (AHP) and its generalization to dependence and feedback, the Analytic Network Process (ANP), are methods of relative measurement of tangibles and intangibles. Being able to derive such measurements is essential for making go

Saaty TL (2008) Decision making with the analytic hierarchy process. Int J Serv Sci 1:83. doi: 10.1504/IJSSCI.2008.017590

Saaty TL, Peniwati K (2008) Group decision making : drawing out and reconciling differences. RWS Publications

Sangle S, Babu PR (2007) Evaluating sustainability practices in terms of stakeholders' satisfaction. Int J Bus Gov Ethics 3:56. doi: 10.1504/IJBGE.2007.011934

Shiau TA, Chuen-Yu JK (2016) Developing an indicator system for measuring the social sustainability of offshore wind power farms. Sustain 8:. doi: 10.3390/su8050470

Šijanec M, Žarnić R, Šelih J (2009) Multicriterial sustainability assessment of residential buildings. Technol Econ Dev Econ 15:612-630. doi: http://dx.doi.org/10.3846/13928619.2009.15.612-630

Sipahi S, Timor M (2010) The analytic hierarchy process and analytic network process: an overview of applications. Manag Decis 48:775-808. doi: 10.1108/00251741011043920

Sólnes J (2003) Environmental quality indexing of large industrial development alternatives using AHP. Environ Impact Assess Rev 23:283-303. doi: 10.1016/S01959255(03)00004-0

Stahl BC, Coeckelbergh M (2016) Ethics of healthcare robotics: Towards responsible research and innovation. Rob Auton Syst 86:152-161. doi: dx.doi.org/10.1016/j.robot.2016.08.018

Stilgoe J, Owen R, Macnaghten P (2013) Developing a framework for responsible innovation. Res Policy 42:1568-1580. doi: http://dx.doi.org/10.1016/j.respol.2013.05.008

Strand R, Spaapen J, Bauer MW, et al (2015) Indicators for promoting and monitoring Responsible Research and Innovation Report from the Expert Group on Policy Indicators Vaidya OS, Kumar S (2006) Analytic hierarchy process: An overview of applications. Eur J 
Oper Res 169:1-29. doi: 10.1016/j.ejor.2004.04.028

van de Poel I, Asveld L, Flipse S, et al (2017) Company Strategies for Responsible Research and Innovation (RRI): A Conceptual Model. Sustainability 9:2045. doi: $10.3390 /$ su9112045

von Schomberg R (2011) Prospects for Technology Assessment in a framework of responsible research and innovation. Tech abschätzen lehren Bild transdisziplinärer Methoden 39-61. doi: 10.1007/978-3-531-93468-6_2

Wu X, Cui P (2016) A Study of the Time-Space Evolution Characteristics of Urban-Rural Integration Development in a Mountainous Area Based on ESDA-GIS: The Case of the Qinling-Daba Mountains in China. Sustainability 8:1085. doi: 10.3390/su8111085

Yüksel I, Dagdeviren M (2007) Using the analytic network process (ANP) in a SWOT analysis - A case study for a textile firm. Inf Sci (Ny) 177:3364-3382. doi: 10.1016/j.ins.2007.01.001 